\title{
7 \\ Entrepreneurship and Social Action Among Youth in American Sāmoa
}

\author{
Aaron John Robarts Ferguson
}

\section{Introduction}

Like many high schools across the mainland US, grad-week in American Sāmoa is a lively time of celebrations for youth and their families. Days at the beach, class trips to the movie theatre and $u m u$ (earth oven barbeque) all serve as a lead-up to the graduation ceremony in which hundreds of families will come to honour the accomplishments of their graduating youth. But, behind these celebrations lies the fact that within a few short months, as many as half or more of those graduating youth will be leaving the islands on which they grew up. Youth leave to seek jobs to support their families, pursue education and find a new life in the Samoan diaspora, moving to destinations as varied as Hawai $i$, Alaska, the Pacific Northwest (US) and California. As Samoan youth age, they are increasingly exposed to a local discourse of success and opportunity that reinforces the defined pathways that draw youth away from the islands. This discourse emphasises success as an exterior 'other' to be pursued away from the local.

Throughout the day-to-day conversations during my research in American Sāmoa, both youth and adults expressed worry about the perceived lack of opportunities. The successes and failures of youth and their effect on the 'aiga (family) and nu'u (village) were frequently used as a measure 
of island success and prosperity for the Samoan people. Worries about youth economic opportunities would thus often segue into worries about the economic state of the island as a whole. Across ages, my contacts evoked a deep concern for the future of the islands' youth and the limits that youth must navigate in their transition to adulthood. These worries manifested when considering the status of the education system, the morality of youth and their attainment of classic Samoan ideals, such as usitai (discipline), and in frequent references to the 'disconnect between youth and elders'. Three pathways have emerged as the most prominent and referenced futures available for young Samoans: military careers, sports scholarships to colleges on mainland US and work at on-island tuna canneries. Recent scholarship on American Samoan youth has focused on the significance of sport in the production of youth futures (Kwauk 2014; Uperesa 2014a, 2014b). This chapter instead explores how youth entrepreneurship is an alternative for young Samoans to attain social and economic capital. Through three illustrative cases, I demonstrate how certain youth have made substantial contributions to re-signifying 'business' as a category of fa'asāmoa (the Samoan way) or 'Samoanness'. By representing business as a form of social action that is motivated by service to the greater community, they thereby articulate global youth culture within their local context.

This chapter is based on two and a half months of ethnographic fieldwork in American Sāmoa between May and August 2015, involving networking, semi-structured interviewing and focus groups with young people between the ages of 15 and 30, as well as with their families and community members of various ages. I begin by examining contemporary scholarship on Samoan youth specifically, followed by a discussion of relevant anthropological literature on globalisation, youth and social capital more broadly. Following that, I introduce three case studies, each of which focuses on a youth business owner whose experiences exemplify the successes and challenges that youth face related to the discourse of restricted opportunities. The first is centred on Pacific Origins, a clothing company built around the juxtaposition of global and local culture through acts of capitalistic value creation, showing how skilfully intertwining global and local influences can lead to a prosperous business and social life on-island. The next case considers Sāmoa's Finest, a tatau (tattoo) shop run by local Army reservist, Sonny Lavea, and highlights the topics of land ownership and military service, illuminates factors that enable success for youth business owners and reveals certain barriers that might impede business creation. Finally, the third case examines 
Sāmoa Office Supply, a one-stop shop for office supplies and electronics. Run by 28 -year-old Jordan Lotomau, this example details fáasämoa as materialised in the realm of business and further demonstrates how these youth have tied their entrepreneurship to social action.

I analyse each case along five interconnected conceptual categories: economic capital, social capital, technology utilisation, mediation of global and local influences, and the articulation of business as a form of social action. These were the most potent themes that emerged during my research into youth futures and, while they are not exhaustive, they allow access to a wide range of relevant factors in a concentrated manner. Hopefully, they help the understanding of some of the central questions animating this research: How do youth come to make these complex decisions about their future? What alternatives exist when youth feel unfulfilled by the conventional futures afforded to them? How do contemporary youth feel connected with fa'asamoa? I conclude that youth entrepreneurship in its formulation as a form of social action and as a re-envisioning of participation in local life, while restricted by certain factors, is a valuable alternative that helps Samoan youth relieve the tension between life on-island and a life in the diaspora.

\section{Globalisation, Capital and the Anthropology of Youth in Sāmoa}

The most current scholarship on Samoan youth has focused on youth involvement in sport, as observed most notably in the work of Fa'anofo Lisaclaire Uperesa and Christina Kwauk. In 'Seeking New Fields of Labor', Uperesa details how American football has become a central channel for youth future development and explores the connection between football, the history of US imperialism and how local structures of opportunity have evolved in American Sāmoa (Uperesa 2014b). At the heart of this process is the ever-present question of American Sāmoa's territorialityspecifically, the uncertainty of American Sāmoa's status throughout its history as a US territory (Droessler 2013). Regarding football as the intersection of 'local and imperial interests', Uperesa demonstrated how football has become a 'conduit' bringing Samoans through mainland educational institutions (Uperesa 2014b). This is further supplemented in 'Fabled Futures', in which she underscores the extent to which Samoan youths' navigation of the enmeshed logics of the football industry is central to the transnational movement of youth (Uperesa 2014a). For 
young Samoans, the often-referenced preponderance of Polynesians in the NFL, and the now multi-generational history of prominent Samoan footballers, serves as a potent force that draws young Samoans offisland. This construction of the so-called 'Polynesian pipeline' effectively legitimates football as a powerfully desirable paradigm for achieving economic prosperity for young (male) Samoans. The limitations of this 'pipeline' (for girls especially) is a reality rarely addressed in public discourse on youth futures.

'No Longer Just a Pastime' builds on this analysis of the role of sports in youth futures, instead focusing on rugby in (independent) Sāmoa (Kwauk 2014). Her exploration of sports as a path to success, a veritable ticket to 'the blessed life', particularly shows the extent to which sport has become instilled within contemporary Samoan culture as a legitimate means of 'personal and professional development' (Kwauk 2014, p. 304). Highlighting that sport itself is an alternative to traditional economic training (such as agricultural work, or professional and vocational education), Kwauk (2014, p. 304) showed how this alternative is essentialised as a form of tautua (service) to the aiga. With sports development directly contributing to the transnational extraction of Samoan youth, life on-island is problematised when success becomes a reality that is exclusively exterior to island life. In such a climate, 'concerns about youth unemployment are thus concerns about whether and how youth can become productive contributing members of their äiga in an evershifting and uneven global society' (2014, p. 316). Though primarily focusing on youth sport development to reach deeper issues such as the legacy of colonialism and health development strategies, the current scholarship has accomplished much to diversify the scholarly attention on youth in Sāmoa expanding into new grounds since the work of Margaret Mead.

Indeed, the legacy of Margaret Mead's Coming of Age in Samoa (Mead 1973) remains pertinent and she is still a well-known name among Samoans. The book brought Mead and anthropology into focus in the US, but it became a source of controversy regarding subject representation and anthropological method (Shankman 1996). Despite the contentions that emerged since its publication, it is significant as the first anthropological contribution to the study of youth in the Samoan. While it perhaps has more to reveal about the writer and the state of anthropology at the time, it remains a useful source to reflect on certain features in the life of Samoan youth-namely, the importance of age-based respect and obeisance, the intricacy of family life and an introduction to core values of Samoan culture. 
Additionally, Mead's ethnography is representative of a cross-cultural or comparative approach that dominated the anthropology of adolescence at the time, but which has transitioned to an 'anthropology of youth' (Bucholtz 2002, p. 1). This has brought forth a more encompassing approach with fewer limitations because of its lack of adult-centric, teleological perspectives of youth. Mary Bucholtz contrasts such perspectives that considered adolescence a mere stage of incompleteness on a transition to adulthood with an approach that views youth as a 'flexible and contestable social category', one in which youth is not a 'trajectory' or aim, but an identity (Bucholtz 2002, pp. 528, 532). This theoretical shift is significant because of the greater appreciation that it allows for the agency of youth in the process of their own sociocultural definition and formation as a peer group.

Globalising youth research, as Bucholtz highlighted, is an endeavour that is not so much 'cross-cultural as it is trans-cultural' (Bucholtz 2002, p. 543). Critically, this transcultural approach enables recognition of the shared experiences of youth as a social group across the Pacific, a connection that is evoked directly by the lived experiences of the youth examined in this chapter. It can be observed, for example, in their engagement with intercultural, digital diasporic spaces that proved to be essential grounds for their business development, or in their use of entrepreneurship as a tool to resolve tensions that they faced in regard to the lack of adequate employment, a reality that many youths face throughout the Pacific Island community (Secretariat of the Pacific Community 2015, p. 24). This transcultural, and even trans-oceanic, approach is also reflected in recent scholarship, including Kwauk's and Uperesa's works in the Samoan islands and Mary K Good's work on gender dynamics and experiences of marginalised youth as they interpolate influences of globalisation with notions of morality and 'modernity' (Good 2012, 2014).

There are several key features from the broader anthropology of globalisation to keep in mind precisely because of the ever-growing influence of 'the global' in the lives of Pacific youth. The first is that globalisation has 'dislodged' culture from certain locales (Inda 2006, p. 11). This dislodging encourages the conditions that allow a blending of global and local influences that youth must, in turn, interact with. The example of American football as a prism that reveals American Sāmoa's history of imprecise colonial relations with the US is one prominent example that shows this in operation, but it can be observed in the general influence of globalisation in the Samoan archipelago as a whole (Macpherson \& 
Macpherson 2009). In such circumstances, certain youth can capitalise on the mastery of the negotiation between those two realities, as will be demonstrated in the examples of Pacific Origins and Sāmoa's Finest. Insofar as globalisation implies a 'heightened entanglement of global and local', those in a position to 'disentangle' those realities become powerful agents in the process of defining youth identity locally (Inda 2006, p. 9).

Due to the acceleration of 'flows of capital, people, goods, images, interactions and processes', those with the means to access appropriate technology may find themselves poised to take advantage of this increased mobility of cultural flows (Inda 2006, p. 9). In this connection, the value of social media and the internet as a tool of commercial expansion places contemporary Samoan youth in a unique position to create new economic opportunities in which previous generations were more limited. It also acts as prime influence on the constitution of diasporic communities into a kind of 'digital diaspora', in which youth on the islands and those in trans-oceanic spaces knit together their ability to engage in shared experiences (such as the passing of a beloved public figure) (Burroughs $\&$ Ka'ili 2015). Youth on-island especially benefit in this regard from a higher likelihood of having regular internet access at school, as compared to many households that are still without adequate connection to the internet. The incorporation of technology has brought significant advantages in each case reviewed here. Sāmoa Office Supply sells computer and office technology and also functions as a small internet cafe. Pacific Origins and Sāmoa's Finest both interact extensively through social media with the youth of the Samoan diaspora and with other Pasifika communities. This showcases how social connections that cross 'time and space' are now 'less dependent on circumstances of co-presence' and how nodes of economic capital are increasingly inseparable from a sizeable, dispersed network that is independent of locale (Inda 2006, p. 9). Throughout these examples, the youth's ability to manage the interwoven global and local realities prove to be pivotal components of their business success.

\section{Pacific Origins}

It seems that there are more airways for the young Samoan than roadways. Arriving as I did at the beginning of summer, I was unprepared for more than half of my initial youth contacts to leave within even just a few weeks of meeting them. They followed grooves formed by the many who 
travelled before them, and whether in search of economic prosperity or sporting success, the paths they took were well worn. For those with the financial means, such as Tai Saifaga, these channels afford access to transnational networks and experience of life off-island. After leaving business school at the University of Hawai' $i(\mathrm{UH})$ Mānoa with his degree unfinished, by age 23 , he became an award-winning business owner with a shop in a prime location in a commercially developed centre of Tutu 'ila. A forward-thinking young man, Tai is thrilled by opportunities to share the vision of his company and his vision for its growth. His company is an effort to create meaningful connections to the past through clothing, so that youth can 'wear [their] heritage'. By offering clothes that blend global fashion with locally designed motifs, Pacific Origins becomes an intermediary of global and local culture and a commodity is constituted through which youth acquire a certain connection to Samoan culture. This act of economic value creation is intimately tied with the accrual of social capital that is generated in part by Tai's mastery over this process of intermediation and through his role as a purveyor of desirable products. Social capital is generated from local artist patronage by sponsoring events for American Samoan youth, and it is reinforced through the use of social media. Tai is thus able to articulate his business as a form of tautua to his 'aiga, his island, and his fellow youth, all in an effort, he says, to 'help inspire his generation to be leaders and connect with their heritage'.

Before opening a storefront, Pacific Origins was run out of Tai's dorm room at UH Mānoa, a compelling story that was articulated skilfully when he and I met. However, it was Tai's experience at the American Sāmoa Community College, before UH Mānoa, that inspired him to create Pacific Origins:

From 2009 to 2011, I was in the community college, and my friends and I would practically live in the art room, but the stuff would just sit in the room; you'd have one art show a semester, but only a few would sell, if that.

Seeing a potential market for Pacific designs, Tai first began selling at UH Mānoa, but later decided to leave college and return to American Sāmoa to expand his business at home, deftly taking advantage of an already established network of business and social contacts that was cultivated through friendships, family ties and interpersonal acuity. Indeed, the speed of our mutual connection on a shared interest in youth streetwear and entrepreneurship demonstrated neatly how Tai had learned to thrive 
in the fabric of global youth fashion. That our rapport was built so readily on this basis emphasised our shared experience as youth despite the distance in space and time between our upbringings.

We spent much of our conversations exploring the core mission of Pacific Origins, which rose beyond just selling inspiring clothing pieces. As Tai described, it involved the creation of culturally relevant clothing that blended elements of global youth streetwear with traditional Samoan and Pacific visual motifs, which was exemplified in the motto 'wear your heritage'. Another key element was the involvement of local youth artists in the production of these wearable signifiers of cultural heritage for youth Samoans. Online, statements about the art and its relevance to youth life are paired with items to generate trans-historical and transnational semiotics: 'Wherever we travel, we carry a piece of our traditions with us. Embrace your lineage'. The storefront itself is a mix of Pacific Origins clothing and popular youth streetwear that Tai orders online or buys when travelling. Travel is promoted as a prominent element in the lives of youth, and special sales are often posted for 'flight nights' - the two days of the week that passenger flights leave the territory. Given this shared reality of travel and migration, many shirts feature designs that Tai hoped would represent Samoan culture for youth abroad. Others are more locally focused, such as one design that was dedicated to an honoured reverend who had recently passed away, or another that was designed for a local school's sports team; even so, both offer a distinct window into island life and the shared cultural experience of the many friends and family who have left the islands.

By transcending the basic demands of mere clothing, Pacific Origins purposefully crafted pieces that offer youth enfranchisement within a community of 'forward thinkers', youth-centric artists and others who cultivate a new relationship with art and heritage. Tai himself actively crafts such a persona through a fashioned presentation, a kind of informal uniform no less constitutive than the tie and button-ups adorning any local Mormons. Sleek, manicured and contemporary fashion is a badge of connection to a scene of global youth fashion, even when one is seemingly far from the production centres of what's 'in' on the street. All it takes is a keen eye to recognise it and, in Tai's case, to reformulate it within the Samoan context. 
This interplay of global influence and local culture is elemental to the selection process of what clothes to print. As Tai explained, 'It's been a learning experience trying to cater to the local kids with the streetwear, but also to the off-island market with the island-wear'. The internet functions as a medium of transmission between these two domains. Social media platforms such as Instagram, Facebook and Twitter are vehicles of communication between Samoans locally and abroad. Spaces on the internet become inhabited in a distinct socio-spatial way, much like their Pacific brethren in Tonga (Burroughs \& Ka'ili 2015). Frequent travels by the young afford opportunities to cultivate trend awareness and marshal that knowledge (and buying power) into local credibility and into being fashioned by such interconnection.

For a youth entrepreneur like Tai, the internet is the technological framework through which economic success is attained. Brand awareness for his business was built through an interaction with thousands of followers across different platforms and by the consistent online activityincluding special sales, updates on upcoming events such as open mics (freestyle talent and art exhibitions) and hints at new apparel. It was on the internet that Tai first perceived the broader potential for Pasifika designs. 'What really inspired me honestly, was Tumblr,' Tai explained. After starting his own blog and seeing the major interest in 'Polydesigns' online, Tai recognised the potential for combining Polynesian patterns with contemporary youth streetwear. Tai observed many of his artistic friends 'drawing on whatever they could get their hands on: CD covers, lampshades, shoes'. Later in Hawai' $i$, he designed his first shirt by combining a trending T-shirt design with 'poly-motifs'. After becoming popular in Hawai' $i$, often selling out of his suitcase or dorm room, Tai decided to move home and centre the business on his home island. Embedding himself on-island proved to be a pivotal choice for his business ethos, as it firmly oriented it within a unique position that was astride the connections between local and global.

Since his move back home, community involvement has become a key part of how the business became a mode of social action rather than just a clothing company. Classic ideals of power and political involvement would have motivated young Samoans to look forward to attaining matai titles, becoming a church leader or obtaining government positions. In response to the limited availability of those classic routes, many of the youth may be left to contemplate other means of contributing to the 
betterment of the islands. Tai consciously develops his vision of social action with this in mind, which leaves him in a unique position to pursue alternative pathways.

Tai described his business model as the 'art of expressing island culture through exclusive merchandise'. Expressing business as an 'art' is a significant shift in vision from what many of my contacts described as the 'disinterested' approach that they noted as common to many Samoan businesses. The company purposefully valued youth art to support the artistic character of youth as a social class - this meant not just the neighbourhood youth or his network of friends, but any youth with the talent to craft stylised island designs. One way this was materialised during my visit was through offering valuable wall space (a significant sacrifice for a small fashion store) for an ongoing art show, giving youth a new space to share their artwork and further promoting a connection between enigmatic visual traditions in a culturally relevant manner. Many works of art dealt with historic themes and core elements of Samoan culture that the youth felt they needed to comment on, or that they felt disconnected from and, through this art, they tactically confronted the distance that some felt with the past. One pertinent example hanging in the shop was a painting of a taupou, a ceremonial role performed by the daughter of a village matai (chief). This otherwise classic depiction of Samoan culture was disrupted by the untraditional colours of the taupou, who stared forward while gleefully sticking her tongue out. This showed the kind of artistic play with which youth could reformulate classic motifs within contemporary constructs of space, time, culture and place. Tai placed great focus on finding ways to feature such art on shirts, giving youth the opportunity to visibly represent their interpretation of Samoan culture wherever they may be.

Alongside artist collaborations, Tai also sponsored events such as monthly open mics (by offering performance slots for any artists who signed up) that featured music, poetry, dance and visual media. Performances were captured on video and shared through social media, which offered exposure and gave Samoan youth opportunities to share their voices across online youth spaces. The events were free and open to all young people, and Tai actively sought to create an atmosphere that promoted collaboration, artistry and inclusion. 
All these elements form the foundation of Tai's business ethos, through which he pursues a specific vision of tautua that extends beyond the family and village and outwards to youth as a social class. These service acts are constituted as a kind of heritage-based commodity that generates appeal based on notions of 'exclusivity', a feature sought by youth who desire popular fashions from abroad and who simultaneously search for meaning that is derived locally from classic Samoan visual traditions. Founded in part on the displacement that youth felt as locals with transnationally rooted desires, Pacific Origins aimed to relieve the tension between the desires for access to global culture and the constraints of evocative notions of authenticity that are rooted in being 'local'. This case thus deals directly with questions of how youth find a fulfilling future onor off-island, how they define what 'the good life' looks like 'on the rock' and the nature of the social action that young business owners pursued. With a goal to 'educate, encourage and inspire', Pacific Origins pursued a vision of social action that intertwined capitalistic appeals with the youth's affinity for a locally meaningful, globally influenced youth culture. Such an approach towards social action allowed for a reconstitution of that social action, as more youth are brought into this social sphere of artistically minded, transnationally oriented young Samoans. Pacific Origins built an experiential product-oriented relationship to Samoan culture through the provision of heritage items, and by promoting participation in sponsored events that contributed to an enlivened youth social atmosphere. Among youth who frequently deplored that 'nothing happens here', I encountered excitement and motivation for this kind of activity in the youth community.

Overall, this case represents an iteration of tautua that applies less exclusively to the family; it rather encompasses the youth of the islands and those abroad instead of just those of a particular village. In this way, a kind of 'trans-family' is created from the interaction of the youth's experience with the contemporary iterations of local and historical tradition and the realities of travel and life outside the islands. Social action, as envisioned in Tai's business, involved sponsorship of artists by cultivating his function as a role model for other youth and by providing clothes that are imbued with a relationship to Samoan heritage. At other times, his social action involved supporting local causes, such as offering donations and shirt designs to local children's sports teams. As Tai expressed it, 'Small, local contributions can go a long way. Never doubt the impact you as an individual can make in the community around you'. All these channels 
of action form the foundation of how he considers himself contributing to the broader social good of American Sāmoa. This articulation of social action blends tautua (service) and galue (work) and is brought to fruition not through the public sector via the classic ideal of Samoan political involvement, but rather through the infusing of youthful energy and vision into the private sector.

\section{Sāmoa's Finest}

Social buzz is not the only buzz that Samoan youth are generating. The buzzing of tattoo guns can be heard often, and the practice of tatau is alive in the minds and hearts of youth artists. The buzzing alone is enough to make your back quiver, even though the pain that comes is welcomed with purpose because of its deeply symbolic role in Samoan culture. The tattoo needle is transformed in the capable grip of the modern-day tufaga, the crafter of the tatau, who skilfully melds ink into the blank canvas of your skin and turns your body into a lively signifier of Samoan art. Sonny Lavea was one such artist who I met, and he did not take walk-in appointments, though he loved visitors. While most tatau artists came to their client's homes, he was an artist with his own studio and his walls displayed this passion for art as well his own tattoos did. Appointments were easy to set up if one had the time to wait until he was available, as his time was desirable and caught between being a family man, an active Army reservist and a young businessman. Still, one could walk in at any moment to talk design, buy new shop merchandise or even meet up for his fitness group. That openness was characteristic of Sonny and his approach to running his shop, which thrived at the intersection of deft social media usage and the combination of Sonny's skilled deployment of tatau as evocative signifiers of Samoan visual culture with his devoted and disciplined outlook. This case examines these features of Sonny's approach, highlights the value of land access as a paradigm in business creation and economic success, explores military careers as a kind of entrepreneurial economic venture in their own right and further illustrates the role of youth in refining contemporary iterations of traditional practices.

Tattoos are often one of the first things that come to mind when people think of Samoan culture, but in American Sāmoa, there are only a few shops. With most tatau artists working from home, having a shop involves a greater allotment of time and the potential for a higher level 
of risk because of rent and maintenance costs. Risk was commonly expressed as one of the largest barriers that prevent youth from pursuing their business ideas. Sāmoa's Finest, one of the premier tatau shops on the island, obviates this risk by situating the shop on family land-which is a strong potential benefit for Samoan families with land and the right location. Sonny, an Army reservist in his late 20s, turned his art into a regular source of income after returning to American Sāmoa from active military duty. Much like Tai with Pacific Origins, Sonny capitalises on his talents through the provision of cultural signifiers, albeit in a more permanent medium.

His art is one of precision, of focus. His tattooing is a steady, rhythmic hum that stops and starts, more like a pulse than anything else; it came and went effortlessly and it is part of the allure of the experience, despite the inherent discomfort involved. His studio is a mere football's throw away from the open ocean, it was renovated out of a once unused portion of a family property and it is prominent and hard to miss, as it rests on the road between shopping centres in Nu'uuli and the government and fish factory centres in Pago Pago harbour. Settled in this ideal location, his shop did not need to stand out from any other building, as the only other building was his own cousin's clothing shop next door. One day, after a visit to the shop, I noticed how close it was to the trails that wound their way up the steep and thickly forested mountains that loomed over the two-lane road caught between land and sea. At the top, old navy embattlements rested, unused. They were placed to defend Tutu ila in the Pacific War, but now they faded into the landscape almost unnoticed. To me, it felt oddly significant to find those guns watching over the narrow stretch where Sonny, upholding a history of Samoan military enrolment, found a better use for a tattoo gun.

Much like those cannons, seeing but unseen and faded into the foliage, the history of militarisation in American Sāmoa lingers, blending into the background of life on-island. Since the last century, Samoans have continually marched through the ranks of the military, perhaps like the rhythmic pulse of a drum, or a tattoo gun. It was during deployment, of all places, when Sonny honed his tattooing skill on all-too-willing fellow soldiers who must have felt cavalier in inviting an untrained Samoan to permanently mark their bodies, trusting his cultural acumen alone. It was as good a place to start as any, but it was certainly not part of the career skills advertised in recruiting centres on-island. 
For Sonny, opening a shop turned a hobby into a regular income, which was supplemented by his continued military service as a reservist. With an established shop built on years of tattooing experience, Sonny benefited from a wide range of clientele, many of whom are Samoans visiting the islands for the first time, but also from visiting non-Samoans. Key to bringing in that demographic is Sonny's social media presence.

Like many of the youth in American Sāmoa, Sonny graduated from high school and entered the military. Frequently referenced as the highest per capita-contributing state/territory to the armed forces, American Sāmoa's deep history with the US military is manifested in the prominence of military careers as a core pathway for youth. American Sāmoa was considered a prized possession of great military significance for the US imperial scheme of the Pacific, which motivated US interests in the islands (Droessler 2013).

Sonny's development of his family land is an example of a unique benefit to business-minded young Samoans; those with access and a prime location can gain an advantage by avoiding prohibitively high overheads from monthly rent and decreasing potential risk. Other youth-run businesses that I encountered, such as a barbershop and a smoothie bar, similarly used this to their advantage. Tattoo work is a particularly desirable pathway, as it requires only investment in a tattoo gun and ink; it can stay a profitable part-time hobby, or it can transition to full-time or supplementary work. Sāmoa's Finest operates for many as a connection to their Samoan heritage, especially for those who live in the diaspora. Much like Pacific Origins, Sāmoa's Finest acts as an intermediary of access to cultural formsthe tatan itself thus becomes a form of capital, emblematic of a bridge between contemporary and traditional Samoan visual traditions. They derive their value directly from a customer's desire for visual designations of fa'asamoa, and getting a tatau done on the island is highly appealing to Samoan youth visiting for the first time and looking for 'the real deal'. For Sonny, this desirability is both a source of obtaining clientele and of derived authentic Samoanness. In this connection, he actively cultivated links to the diaspora through frequent posts on social media, spreading his art through online spaces and generating future clientele.

As with Pacific Origins, economic and social capital are intertwined through this use of social media for promotion and awareness and as a platform for showcasing tatau designs and connecting with customers. Photos with customers after most sessions documented new designs 
and were posted on the Sāmoàs Finest Instagram account, often with the customers tagged, which built a sense of camaraderie. These pictures spread widely through the use of prominent tatau-related hashtags that connect the business with emerging social media discourses that venerate Polynesian design. \#Polyart, \#Polytattoo, \#tatau and other hashtags that frequently accompany tatau-related social media work to transform the tatau from a design tradition that is rooted within each specific island to a potent site used for the confluence of broader regional influences. This is even reflective of the mixed background of any potential customer who may have relatives or ancestors from different island groups, who can have their mixed heritage represented through the syncretism of multi-island art traditions. By combining inspirations from different trends in tatau design and by participating in the extensive social media landscape of Polynesian designs, Sonny's tatau work is representative of an inter-island, trans-oceanic contemporary art form. In this scheme, these interstitial connections become as much a form of capital as his skill at wielding a (tattoo) gun. Further, this arrangement reveals a particularly Samoan context of youth business creation that relies on an influx of social capital that is built on the strong connections of Samoan youth in diasporic spaces, which is then, in turn, marshalled towards economic success.

Sonny's life as a reservist is threaded through his service to his family and island and it connects him to many Samoan families, both past and present. His everyday life and relations are intertwined with his military work. His wife is also an enrolled reservist and his children may very well grow up to be the same. It is difficult to overstate how ever-present this militarised life is across different social circles; yet it often simultaneously plays out in the background, undiscussed. It is, however, a viable economic pathway for Samoan youth, one which many youth take to with as much vigour and spirit as they take to sports. It could even be regarded as a kind of essential entrepreneurial opportunity, as it is difficult for so many to attain an economic livelihood and generate prosperity for the aiiga. For Sonny, who returned to the islands after active service, it became a foundation for his business success and the start of his family life. Military service was interlaced with tattooing from the beginning.

By successfully capitalising this form of Samoan culture for Samoans both young and old, by harnessing family resources and extensive word-ofmouth and social media advertisement, Sonny acts as a kind of gateway for tattoo-seeking young Samoans wishing to adopt a supremely valuable signifier of Samoanness. Tattooing for Sonny was simultaneously an 
enjoyable art, a profitable livelihood and a way for him to serve others through the production of meaningful identification with traditional Samoan art. It is supplementary, and complementary, to his work as a reservist and as a fitness instructor, all of which are viewed as his contribution to his community. In terms of social action, Sonny is typically demure and does not hold any overly grand opinions of his contributions, though he clearly values the function that he has and the service that he provides as a skilled neo-traditional tufaga. His military service, life as an engaged community member and role as an intermediary for some of the most valuable emblems of Samoan visual tradition are all interwoven and vital to his life as a young Samoan who returned to his island from abroad, who might have just as likely been taken away either by the economic demands or by the other military postings, like so many other militarydriven Samoan youth.

\section{Sāmoa Office Supply}

Jordan Lotomau is the 28-year-old business owner of Sāmoa Office Supply, a popular shop for office supplies, printing services, electronics and more. His parents bought the business when he was young, after migrating to American Sāmoa from Sāmoa. Like other Samoan children and teens, Jordan was raised working alongside his parents at their business and he took over running the store when his father passed away. This case exemplifies a common pathway to business in Sāmoa, whereby business ownership is passed through the family. Like Tai, Jordan also studied business in college off-island and this experience led him to direct his efforts towards building a future at home rather than one pursuing business in the diaspora. Sāmoa Office Supply sells new technology to local offices and families and it functions as a small internet cafe. Numerous local businesses and government offices print their business cards, flyers and other print materials in his shop. As a result, Jordan is a well-known and respected young adult businessman.

For Jordan, his business is both an end, as it is a livelihood itself, and a means to an end, as it functions as a conduit for his vision of social action. This social action is intimately tied to his ethos of business, which is founded on discipline and cooperative family involvement in the business. Jordan's business success and the cooperation of his family allows him to pursue a vision of tautua, primarily through his role as a coordinator of an 
island-wide program that focuses on creating community service groups for Samoan adolescents. Rather than regarding business and service as separate, he enacted both in his galue out of the principle of offering tautua to his family and to the Samoan people. Much like Tai, he saw all the youth of the island as a distinct social group with specific needs. He regularly facilitated gatherings of youth whom he mentored, and he encouraged their involvement in community activities, especially acts of service aimed not just towards their elders, but also towards younger youth.

The key defining feature of Jordan's approach to business is the significance of the 'aiga. and this speaks to the centrality of family in the decisionmaking process for Samoan youth as they think about their future. For Jordan, involvement with the family business was encouraged early on, when his family moved to American Sāmoa in search of economic opportunities. From the beginning, his family was very supportive of what he wanted to do. As he reflected on the value of their support, he recognised how, 'in many ways, everything was placed in front of me, so I went for it'. His parents strongly emphasised the value of education and, by the time Jordan graduated from high school, they had built the economic capital to support him through college. Jordan adopted this long-term vision himself and spent eight years off-island, including five at UH Mānoa, studying business and another three years offering volunteer religious service at the Baha'i World Centre in Haifa, Israel.

This extended period off-island proved fundamental to inspiring his personal vision and encouraged him to return to focus on a life of service to his home island. The transition to college was difficult and the academic rigour was challenging in comparison to his school experience growing up. For him, as for many Samoan youth, college was an 'eye opener' because of the difference in culture and pace of life. Life off-island was appealing in many ways and he recognised that there were more opportunities for business elsewhere; however, life in American Sāmoa was 'more straightforward' and his time away increased his appreciation for life at home. This was especially cemented by doing volunteer religious service, which strengthened his faith and helped him think more deeply about what he wanted to offer to his home island. Jordan even noticed a major difference in his involvement with the business after returning. Before, he felt more like a labourer, less interested in the direction of the business. After college and life abroad, he truly felt that he had become 'business minded'. Currently, he runs the family business and coordinates much of the family's affairs. 
The story of Jordan's path to business affords valuable reflections of the extent to which entrepreneurship is fostered in American Sāmoa. In certain ways, business activities in Samoan society are actively fostered from a young age. These can be as simple as accompanying parents to work at the market, selling goods on their behalf or working as shop assistants. Samoan children and youth can frequently be observed spending time at the family business and working directly at the stores. Strong oratorical traditions, the strength of family networks and the potential for utilisation of family land all potentially serve to instil entrepreneurial characteristics. Further, it is arguable that the growth of sports development has transformed youth and their families into 'sports entrepreneurs', and accessing sports opportunities often demands a level of business acumen and even family-level coordination. Yet many of my contacts observed that youth and young adults underutilise business creation as a potential pathway. In one interview with the head of the local Small Business Development Centre (an initiative offering training courses and business assistance), this perspective was reiterated in the fact that most of the initiative's consultants were middle aged, showing that perhaps youth may need more support or training to recognise what business opportunities were available. For many of the youth with whom I spoke, when asked what kind of business they would create if no barriers existed, most responded that they had never considered it an option and, therefore, it was not an imagined possibility.

When I explored this with Jordan, he emphasised the invaluable role that his family's support played in leading him to enter business. He channelled that encouragement and early-life training, as well as the economic capital that they had accrued towards further training in college. His formal education in business, combined with his parents' experience and support, proved crucial to his ability to imagine possibilities and it nurtured his capabilities. As much as he realised the value of their encouragement, he also recognised the difficulty in starting a business if you did not have a financially prosperous background. He observed that 'there is a disadvantage for youth in business creation because it is hard to get loans if you do not already have money to start up'. Even simple things such as pressure on businesses through raised licence costs and other bureaucratic hurdles can make youth feel that business creation is out of reach, not to mention the need to contribute to the welfare of their family if they were not in a position to financially consider starting a business. 
As a means for achieving economic security, Sāmoa Office Supply aided Jordan in fulfilling this all-important ability to support his family financially. He held much of the responsibility for family affairs, including taking care of his younger relatives who lived with him at his household. Understandably, family forms a core benefit to the operation of a Samoan business in many ways and this can be observed in Jordan's business ethos. Family members can act as trusted employees who occupy positions at a company and who represent an invaluable resource. Offering business positions is one way of honouring connections to relatives and close family friends. Having 'loyal, honest employees' helped diminish business maintenance costs and kept money within the family-something that Jordan emphasised often. According to his younger relatives, involvement in the business aided them in their dedication to their school work and in developing the hard work and discipline needed for their future. Jordan also sought to instil a long-term vision in them and to mentor them along their path to adulthood, replicating the accompaniment that he himself received.

Besides its family-oriented nature, the business found success directly as a purveyor of technology as a commodity of exchange. Whether in its role as an internet cafe, through offering printing services for a wide range of clients or through selling affordable and up-to-date electronics, his profession cemented an important function for the community of island businesses or for the various Samoans with limited or no internet access elsewhere. However, in this case, the form of business is less important in comparison to Jordan's approach to following his entrepreneurial vision, a vision that I described as needing tender support in the scheme of livelihood opportunities that is offered to the young. Ultimately, the example of Sāmoa Office Supply offers further contextualisation of how business can operate in tandem with core concepts of Samoanness, and it is an example of a common, family-oriented pathway to business attainment for the young.

\section{Conclusion}

From the cases explored here, it is clear that there are distinct possibilities available to youth in the realm of business creation. These possibilities can reshape youth perspectives as they negotiate their futures in light of their familial ties and community needs, and they can reorient and reshape 
their interaction with the landscape of opportunities that is open to them overall. To support this claim, I have drawn on my research with a variety of on-island youth, paying particular attention to these three prominent examples that elucidate how Samoan youth interact with their cultural legacy and the contemporary conditions in their approach to crafting a fulfilling and promising future for themselves on-island.

From these case studies, we can see a snapshot of how contemporary youth are actively engaged in dialogue with the received categories of Samoanness, yet how they are also reflexively redefining how Samoanness is deployed in their life contexts. For Pacific Origins, this involves articulating a sense of Samoan identity and connection to the past through which youth may simultaneously connect with exclusive global youth fashion, as well as locally produced visual art. Similarly, Sāmoa's Finest offers a connection to perceived Samoan identity through the traditional category of tatau. In this way, Sonny operates as a point of access for young Samoans seeking to connect to the past through body modification. Yet, Sonny is not a traditional tufaga, but rather a master of what could be called 'Poly-style' tatau, a widespread art form, given prominence through social media, that incorporates traditional-style designs and integrates them within a rapidly evolving trans-island contemporary art scene. These designs have propagated alongside the Samoans who have brought them into the spaces and places of the diaspora. What differentiates Sonny from other neo-traditional tatau artists is the reverence for his skill and, specifically, the legitimacy granted to him as a 'local' that affords him a position as an authentic purveyor of heritage. This forms much of his appeal and attracts plenty of clients to the door, especially Samoans returning to the island or visiting for the first time.

These two cases are exceptional to some degree. Pacific Origins represents several years of work and benefit from family economic support that allowed Tai to experiment and gradually expand his business as he learned. Land as a form of capital and an already established and successful family business were essential resources that helped him invest time and money in his clothing company, something that may have been prohibitively expensive otherwise. These factors allowed him to transcend the aversion to risk that many youth felt towards following through with a business idea. Additionally, it is hardly likely that many more apparel companies could enter the market without it becoming saturated; therefore, merely replicating such an example is not an adequate solution to the limitations to youth opportunities. Sāmoa's Finest is also exceptional to a degree, 
as it is one of only a few tattoo shops with a dedicated building rather than being an in-home place like most other tatau artists. Sonny's tattoo work was also founded on his military career, and the significance of the cross-section between his army life and his life as an artist is ripe with historical and cultural significance. Sāmoa Office Supply may then serve as a connection to the more common experience of business involvement for youth, and it acts as a kind of prism through which attitudes surrounding Samoan involvement in business may be remapped as existing conditions evolve and potential for new businesses are open to youth, even as local life and accelerating global influence become more entangled.

Finally, it is also important to acknowledge and underscore the limitations of these cases overall. Specifically, besides the economic factors already mentioned in each of these cases that enabled their success, each of these cases represent male youth experiences. Despite it being challenging at times for myself, as a male researcher, to cultivate deeper research relationships with younger Samoan women, it was clear that there was not a lack of young women and girls active in the entrepreneurial space. Indeed, during my time in Tutu'ila, I encountered numerous inspiring examples of young women pursuing business, although my connections with some of them unfortunately did not coalesce into enough rapport for me to adequately portray their experiences in the scope of this work. Future research in this topic would benefit greatly from a more thorough exploration of the gendered dynamics of youth business creation. Aside from these limitations, what remains is to explore how these examples could inform strategies for re-envisioning how youth approach their futures, especially how to respond to the tensions that youth experienced regarding globally located desires and their locally rooted existence. Much could be accomplished in the context of school and family life to support and encourage youths' ideas for business and, even further, to create new opportunities for young people to contribute substantively to the public discourse regarding what opportunities are available and how to address and prepare for the challenges they'll face in the rapidly changing environment at home and abroad. Collaborations with the American Sāmoa government to foster business creation and honour the youth contributing in these spaces would continue to elevate the potentials of this mode of youth activity, and it could even provide opportunities to bridge the apparent 'gap' between the young and their elders. 
This work is primarily a contribution to the scholarly attention that has been given to Samoan youth, but it seeks to broaden the conversation by exploring the socioeconomic implications of youth business endeavours and how these contribute to actualisation of youth a social body. It also serves as the basis for future contributions on youth futures, particularly in the realm of economic strategies and youth relationships with globalisation and digital diasporic spaces. Future research would benefit in this regard by exploring how youth as a social category in American Sāmoa has emerged historically over the course of the last century. Additionally, during my research, I benefited immensely from the sense of inclusion gained by being a youth, indicating that this is a rich area for student anthropologists especially. Further, youth as a research focus was particularly potent, allowing access to a wide range of topics, while simultaneously enabling specifics to be teased out of the complexities encountered in fieldwork. Given that youth as a social class intersect with many issues that are important to Samoan society, and that the stakes of the future are laid on the shoulders of youth who are regarded as the ones who will arise to adopt the legacy of past generations, it is more important than ever to rigorously consider the conditions and character of youth experience and to develop ever more effective ways of supporting young people in attaining prosperous futures.

\section{References}

Bucholtz, M 2002, 'Youth and cultural practice', Annual Review of Anthropology, vol. 31, no. 1, pp. 525-552, doi.org/10.1146/annurev.anthro.31.040402. 085443

Burroughs, B \& Ka'ili, TO 2015, 'Death of a king: Digital ritual and diaspora', Continuum, vol. 29, no. 6, pp. 886-897, doi.org/10.1080/10304312.2015. 1073684

Droessler, H 2013, 'Whose Pacific? US security interests in American Samoa from the Age of Empire to the Pacific Pivot', Pacific Asia Inquiry, vol. 4, no. 1, p. 58.

Good, MK 2012, Modern moralities, moral modernities: Ambivalence and change among youth in Tonga, University of Arizona Press, Arizona.

Good, MK 2014, 'The Fokisi and the Fakaleiti: Provocative performances in Tonga', in N Besnier \& K Alexeyeff (eds), Gender on the edge: Transgender, gay, and other Pacific Islanders, University of Hawai i Press, Honolulu, pp. 213-240. 
Inda, JX 2006, The anthropology of globalization: A reader, John Wiley and Sons, Chichester, UK.

Kwauk, CT 2014, “"No longer just a pastime”: Sport for development in times of change', The Contemporary Pacific, vol. 26, no. 2, pp. 303-323.

Macpherson, C \& Macpherson, L 2009, The warm winds of change: Globalisation in contemporary Sämoa, Auckland University Press, Auckland.

Mead, M 1973, Coming of age in Samoa, Dell Publishing, New York.

Secretariat of the Pacific Community 2015, The Pacific youth development framework 2014-2023, Pacific Community, Suva.

Shankman, P 1996, 'The history if Samoan sexual conduct and tie MeadFreeman controversy', American Anthropologist, vol. 98, no. 3, pp. 555-567, doi.org/10.1525/aa.1996.98.3.02a00090

Uperesa, FL 2014a, 'Fabled futures: Migration and mobility for Samoans in American football', The Contemporary Pacific: A Journal of Island Affairs, vol. 26, no. 2, pp. 281-301.

Uperesa, FL 2014b, 'Seeking new fields of labor: Football and colonial political economies in American Samoa', in A Goldstein (ed.), Formations of United States colonialism, Duke University Press, Durham and London, pp. 207-232. 
This text is taken from Pacific Youth: Local and Global Futures, edited by Helen Lee, published 2019 by ANU Press, The Australian National University, Canberra, Australia.

doi.org/10.22459/PY.2019.07 